\title{
A favelofagia: a criação de um novo cânone literário a partir da favela ${ }^{1}$
}

Favelofagia: the creation of a new literacy canon form the favela

\author{
Luana Loria ${ }^{2}$
}

\begin{abstract}
Resumo: O Bando Editorial Favelofágico é um coletivo literário e uma editora sem fins lucrativos que surge no Rio de Janeiro, no complexo de Manguinhos, em 2015. O coletivo tenciona promover autores das periferias que se identificam com uma perspectiva contra-hegemônica, com respeito ao padrão literário e social dominante, no intuito de construir um movimento literário contra-hegemônico, plural, politizado, engajado, livre dos cânones e sedento de prática e transformação.
\end{abstract}

Palavras-chave: Rio de Janeiro. Favela. Literatura.

Abstract: The Bando Editorial Favelofágico is a literary collective and a non-profit publishing house from Manguinhos (Rio de Janeiro) born in 2015. The collective intends to promote authors from the peripheries who identify themselves with a counter-hegemonic perspective with respect to the literary and social standard dominant canon, in order to build a counter-hegemonic literary movement, plural, politicized, engaged, free from the canons and searching for practice and transformation.

Keywords: Rio de Janeiro. Favela. Literature.

\section{Introdução}

O Bando Editorial Favelofágico é um coletivo literário e uma editora sem fins lucrativos que surge na cidade do Rio de Janeiro, no complexo de Manguinhos, em 2015. O coletivo tenciona promover autores das periferias que se identificam com uma perspectiva contra-hegemônica com respeito ao padrão literário e social dominante, no intuito de construir um movimento literário plural, politizado, engajado, livre dos cânones e sedento de prática e transformação. A periferia é selecionada como lugar plural de fala por parte do Bando Editorial Favelofágico, lugar possível para criação de novos paradigmas e leituras, novos sentidos e percepções sobre essas realidades. Nessa análise, cabe ressaltar a crítica realizada pelo Bando à estética da violência como narrativa dominante sobre a favela, um tema fortemente associado na literatura aos espaços considerados periféricos e carentes, como destacarei. Desse modo, para compreender melhor a proposta do Bando Editorial Favelofágico, introduzo o tópico da favela abordado pela literatura brasileira - particularmente pela literatura marginal -, a que se deve reconhecer uma importante centralidade temática.

\section{Uma breve introdução sobre a literatura da (e sobre a) favela}

O debate sobre a presença da favela na literatura recai comumente no tópico da literatura marginal. Mas o que se entende por essa expressão? No

\footnotetext{
1 Desenvolvo o presente artigo a partir do capítulo 2 da minha tese de doutorado intitulada Manifestações artísticas como contranarrativas: estudos de casos das periferias do Rio de Janeiro e de Lisboa. 2017 (Doutorado Interdisciplinar em ciências humanas) - Universidade Federal de Santa Catarina, Florianópolis, 2017.

2 Doutora Interdisciplinar em Ciências Humanas pela Universidade Federal de Santa Catarina, (UFSC), Florianópolis, SC, Brasil. ORCID: https://orcid.org/oooo-0002-5439-9251. E-mail: luanalo2689@gmail.com
} 
contexto brasileiro, identifica-se como literatura marginal a corrente literária da década de 2000 , nascida particularmente nas periferias de São Paulo, com um viés engajado e politizado, cujos textos se caracterizam pelo uso de uma linguagem coloquial. Na reflexão que sugiro apresentar aqui, observo que a expressão literatura marginal é usada de forma mais abrangente, considerando textos literários engajados ou não, tendo como foco protagonistas, espaços ou temáticas marginais, escritos por autores provindos de realidades periféricas e/ou por escritores pertencentes a outras classes sociais. Portanto, o termo marginal sinaliza um contexto artístico de ampla atuação, não apenas um lugar de enunciação ou a escolha de temáticas e atitudes ideológicas específicas. Nesse contexto, observo que, na literatura marginal $^{3}$, a favela ocupa uma centralidade crucial. Primeiramente, interessa-me refletir sobre esse espaço, selecionado não apenas como cenário, mas também como lugar de proveniência dos escritores, como laboratório cultural, como linguagem. Assim sendo, citarei alguns escritores que escolheram a favela como lugar de representação e como espaço de enunciação, particularmente, no Rio de Janeiro, mas também, em São Paulo. Já na segunda parte deste artigo, apresento e discuto sobre o Bando Editorial Favelofágico, o coletivo literário carioca que chamou a minha atenção por eleger a favela como lugar a partir do qual tecer e propagar narrativas e ficções, detectando nisso singularidades e inovações.

Antes de concentrar-me no tópico da favela, cabe ressaltar que o termo marginal foi usado pela primeira vez no campo literário para designar o movimento de poesia marginal dos anos 1970, nascido no Rio de Janeiro ${ }^{4}$. O movimento, composto por escritores da classe média e média-alta, era considerado marginal pelo tipo de reprodução e circulação artesanal das obras - razão pela qual esse movimento era chamado também de Geração Mimeógrafo -, os poetas eram, ao mesmo tempo, os distribuidores das próprias obras através da "venda de mão em mão, propaganda boca a boca, mantendo um contato presencial com seu potencial leitor em teatros, shows, cinemas e bares" (SILVA, 2008, p. 6). Os meios tradicionais do mercado editorial eram, assim, recusados. O tom irônico, a escolha pelo uso de uma linguagem coloquial, a tematização do cotidiano carioca de classe média são os principais elementos que caracterizam os escritos dos poetas marginais dos anos 1970 (SILVA, 2008). Conforme o que foi dito, é possível observar que a favela, na poesia marginal, não era um tópico central; contudo, ela já foi eixo de muitos textos literários anteriores a essa época. Valladares (2006) apresenta uma cronologia da presença da favela nas artes e retomo, mais especificamente, algumas datas significativas dessa presença na literatura a partir do final do século XIX até meados do século XX:

1898 - Primeira edição do romance $O$ Cortiço de Aluizio de Azevedo 1902 - Primeira edição de Os Sertões de Euclides da Cunha 1908 - João do Rio descreve a visita ao morro de Santa Antonio

1934 - Publicação do romance $O$ bota abaixo, crônica de 1904, inspirada na reforma de Pereira Passos

1935 - Publicação do romance Salgueiro de Lucia Cardoso

1938 - O Jornalista L. Edmundo descreve o morro de Santa Antonio em O Rio de Janeiro do meu tempo"

3 Faz parte da literatura marginal também a produção de escritores que narram histórias em outros contextos, como por exemplo, nas prisões. Um exemplo é o livro Estação Carandiru, de Dráuzio Varella (1999), central na consolidação da literatura marginal, livro que foi também adaptado para o cinema.

4 Na dissertação de Érica Peçanha do Nascimento, intitulada Literatura Marginal: os Escritores da Periferia entram em Cena (2006), discute-se sobre a diferença entre o movimento de poesia marginal dos anos 1970 e o movimento da literatura marginal de 200o: "Cabe acrescentar que esses dois movimentos brasileiros de literatura marginal se concentraram em espaços geográficos diferentes. Os poetas marginais dos anos 1970 proliferaram em maior número no estado do Rio de Janeiro e a nova geração de escritores marginais, constituída por escritores da periferia, é predominantemente composta por moradores de São Paulo - embora seja preciso considerar que os dois estados componham o eixo cultural dominante no país" (PEÇANHA, 2006, p. 20). 
1946 - Elay Pontes publica um romance com o titulo Favela. (VALLADARES, 2006)

Apontando alguns escritores que se alinham nesse contexto, não se pode deixar de citar o já mencionado João do Rio ${ }^{6}$ (1881-1921), que, através de suas crônicas e reportagens, retratou não apenas o "espaço elegante e fútil do dândi [...]”, mas também "o espaço dos operários, tatuadores, fumadores de ópio, coristas, prostitutas, criminosos" (GOMES, 1994, p. 109); descreveu as favelas como "livres acampamentos da miséria”, exaltando, ao mesmo tempo a riqueza cultural dessas, na crônica sobre o celebrado morro de Santo Antônio, publicada no livro intitulado Vida Vertiginosa (1911). João Antônio (19371996) apresentou personagens suburbanos da capital paulista e do Rio de Janeiro dos anos 1960: malandros, jogadores de sinuca, boêmios, crianças abandonadas, prostitutas (BENEVENUTO, 2006). O autor paulista escreveu, por exemplo, a crônica "Testemunho de Cidade de Deus", publicada no livro Casa de Loucos (1976), em que apresenta várias histórias sobre o conjunto habitacional Cidade de Deus, no Rio de Janeiro. Diferentemente do escritor João do Rio, de origem burguesa, João Antônio pertencia ao mundo retratado nas suas obras, assim como Lima Barreto (1881-1922), outra figura literária, inicialmente desprezada pelo mundo literário por ser pobre e negro, que retratava em suas obras os subúrbios cariocas e a hipocrisia da classe burguesa (BENEVENUTO, 2006). O poeta Carlos Drummond de Andrade (19021987) representou a favela em muitos de seus escritos, como no poema "Favelário Nacional" (1984), em que questionava o distanciamento social e geográfico que vivenciava com respeito à favela, contexto que, de fato, desconhecia, como demostram os primeiros versos de seu famoso poema.

Quem sou eu para te cantar, favela, que cantas em mim e

Para ninguém a noite inteira de sexta E a noite inteira de sábado
E nos desconheces,

Como igualmente não te conhecemos? (ANDRADE, 2007, p. 111).

Aponta-se, desse modo, como a favela sempre foi um conteúdo literário chamativo entre a classe média e média-alta, como exemplifica sua presença nas obras de João do Rio e Carlos Drummond de Andrade, e também nas de Patrícia Melo e Rubem Fonseca.

Patrícia Melo escreveu Inferno (2000), um livro que retrata a história de um traficante. Nele, a autora cria uma favela ficcional, o Morro de Berimbau e o descreve:

Escadas e becos, descidas e subidas, escadas, choro de criança por toda a parte, degraus, sobe-e-desce, vãos, muquifos, escadas, trapos nos varais, dobra à direita, esquerda, desce para subir, sobe, degraus, desce, telhados e janelas, a cada dia Reizinho percorria um trajeto diferente, aproveitando a caminhada em direção à parte mais alta da favela, de onde observava a movimentação no morro para os traficantes, para conhecer mais e mais o labirinto e as pessoas (MELO, 2000, p. 102).

Rubem Fonseca escreveu o famoso "A arte de andar nas ruas do Rio de Janeiro", publicado no livro de contos Romance negro e outras histórias (1994), em que retrata o cotidiano, a violência, a realidade dos excluídos e dos marginalizados que dominam as ruas do Rio de Janeiro. Outra famosa obra de Fonseca, Feliz Ano Novo (1975), é uma antologia de contos do início dos anos 1970, censurados por serem textos ferozes, sujos, violentos e pornográficos. O tema do banditismo urbano e a crua representação da violência caracterizam a narrativa desses contos.

Como observado, a favela foi também um lugar a partir do qual narrar e criar contos realistas e ficções, como atestam particularmente as obras de Lima Barreto e João Antônio. A esse respeito Hollanda afirma que

[...] a periferia sempre foi um eixo literário importante. Mas agora, pela primeira vez, desde

5 Registro aqui, que a referida obra consultada não estava paginada.

6 Pseudônimo de João Paulo Emílio Cristóvão dos Santos Coelho Barreto; foi jornalista, cronista, tradutor e teatrólogo brasileiro. 
de Carolina Maria de Jesus (autora de Quarto de Despejo), temos realmente uma literatura feita pelos sujeitos dessa periferia, com uma grande força literária e com forte impacto político (DE HOLLANDA, [2007]).

Carolina Maria de Jesus, mulher, negra, pobre, mãe solteira, favelada, catadora de lixo, é considerada uma figura central no desenvolvimento da literatura marginal que elege a periferia como lugar de fala. Seu livro, intitulado Quarto do despejo (1960), é considerado por muitos como a primeira obra da literatura marginal brasileira. Escrita na época do governo de Juscelino Kubitsheck entre os anos 1956 e 1961 e encenada em São Paulo, nela retratam-se as dificuldades de se viver em meio à miséria absoluta, em uma situação de extremo caos social, econômico e cultural (BENEVENUTO, 2006). O universo representado por Carolina revela-se fortemente dicotômico: o luxo se opõe ao lixo, e a favela se equivale à negação da cidade (FRANCAVILLA, 2012). A autora, que narra o seu cotidiano dentro da favela em formato de diário, expressa o seu desejo de mudança social e de conquista da vida burguesa. Carolina, desse modo, não exterioriza uma visão politizada e consciente da própria condição; efetivamente não questiona e não problematiza a riqueza como origem da exclusão social dos pobres. À vista disso, Carolina irrompe como uma personagem contraditória, complexa, como antimodelo, individualista na busca obsessiva do bem-estar e do sucesso pessoal. Segundo Francavilla (2012), Carolina, portanto, não faz parte do catálogo do romantismo revolucionário sobre o qual a literatura marginal da década 2000 se funda.

Depois da experiência de Quarto de despejo e a partir dos anos 1990, o termo marginal começa a demarcar mais especificamente um grupo de escritores moradores ou ex-moradores das periferias urbanas que relatam, de maneira realista, histórias sobre a própria realidade, ressaltando a posição politizada e engajada de crítica e denúncia social. Os escritores do movimento da literatura marginal apresentam um novo olhar sobre a favela, como afirma Tailze Melo Ferreira (2007) na resenha "Entre Becos e Tetos de Zinco: Paisagens de um Favelário Nacional”, a qual menciona os autores que adotaram essa abordagem e que considera os pioneiros da nova tendência, entre os quais Carolina Maria de Jesus, apesar de ela não se encaixar plenamente nesse perfil, como constatado.

Carolina Maria de Jesus, Ferréz e Paulo Lins participam do grupo de autores que falam do universo da periferia a partir do crivo da experiência pessoal, já que, como moradores de favelas, vivenciaram a difícil ambiência desse espaço. Longe dos padrões culturais estabelecidos no e pelo cânone literário, esses autores utilizam uma linguagem marginal, valendo-se de experimentos lingüísticos (sic) subalternos que parecem tornar mais "reais" relatos de violências de toda ordem. Assim, o universo desses excluídos não está, hoje, apenas nos livros de autores de classe média que o tomam como objeto mas também na escrita de quem passou pela experiência da exclusão. Isto é, se antes esses estratos sociais se limitavam a objeto da escrita de autores de classe média, hoje, mesmo que ainda de forma tímida, nota-se um deslocamento em direção à posição de sujeitos do processo simbólico (FERREIRA, 2007, p. 335).

O tom realista, a estética da violência, a linguagem coloquial e subalterna são elementos que caracterizam a literatura marginal das últimas décadas, literatura que também se designa periférica, cujos escritores tencionam "tematizar seu cotidiano violento, colocar em questão a cultura periférica e acima de tudo inscrever na história um grupo antes silenciado, dando-lhe voz própria" (SILVA, 2008, p. 28). Argumenta-se, assim, sobre a constituição de um novo olhar sobre as favelas: seus habitantes tornam-se os protagonistas das próprias histórias por eles narradas, descrevem suas realidades e representam-se. A favela, assim, vem observada de dentro para fora.

A publicação do livro Cidade de Deus (1997)7 de Paulo Lins, foi um evento pioneiro no contexto da

7 O livro foi adaptado para o cinema em 2002. O filme homônimo foi dirigido por Fernando Meirelles e Kátia Lund. 
literatura marginal. O autor retratou as "experiências urbanas da violência e da exclusão, em especial em formatos que possam reivindicar 'autenticidade' e 'visceralidade' testemunhal" (RODRIGUEZ, 2003, p. 48), da mesma forma que Ferréz e outros "talentos da escrita periférica", como se constata adiante. O livro, baseado em fatos reais, é encenado no complexo da Cidade de Deus, que se faz de moldura para as histórias paralelas de Buscapé e Dadinho e para a guerra do narcotráfico entre facções. A busca da autenticidade através do uso de uma linguagem realista e crua, centrada na estética da violência, pode, por um lado, contribuir para o fortalecimento do maniqueísmo e do essencialismo que domina as representações das favelas, descritas regularmente como lugares violentos. Porém, a reprodução dessa estética e desse imaginário corresponde também a uma forma de denunciar a corrupção da polícia e as injustiças sociais que predominam nessas realidades. A esse respeito, Patrocínio (2006) evidencia que a narrativa desenvolvida no livro Cidade de Deus não nasce a partir de um discurso autônomo formulado pelo "escritor-ex-morador" da favela Paulo Lins; pelo contrário, recupera-se e imita-se o discurso dominante, que contribui para o fortalecimento da narrativa hegemônico-essencialista sobre o marginal, codificando as favelas apenas como espaços degradados, violentos e carentes. Patrocínio (2006) salienta que Paulo Lins, como ex-morador da favela, não foi integrante do mundo do crime que retrata; ele, de fato, está fora dessa realidade e apresenta a perspectiva dos bandidos; escolhe, desse modo, um foco narrativo que "coloca em evidência uma representação da favela muito veiculada na mídia impressa e televisiva, sobretudo nos discursos de caráter jornalístico: a indissociabilidade entre favela e criminalidade" (PATROCÍNIO, 2006, p. 50). Por essas razões e concordando com a perspectiva de Patrocínio (2006, p.61), observo o romance de Paulo Lins "como um capítulo da história da formação da criminalidade nas favelas do Rio e não apenas como a história da formação de uma favela." Os mecanismos da narrativa dominante sobre a favela - como a estética da violência, símbolo que demarca e diferencia o contexto periférico de outros espaços geográficos e sociais -, são reapropriados, portanto, pelos moradores-escritores que, intentam, sim, denunciar a realidade dos fatos, mas que, ao mesmo tempo, impedem pensar em outros e diferentes discursos e narrativas que podem ser tecidas a partir das periferias.

Um livro publicado no mesmo ano do lançamento de Cidade de Deus, escrito por Ronaldo Alvez, ex-morador da favela de Rocinha, é um raro exemplo que diverge do discurso dominante, oferecendo uma leitura diferente sobre a favela. O Bandido e outras histórias da Rocinha (1997) é uma autobiografia do autor na Rocinha, na qual não se dá ênfase ao tema do crime, da pobreza e da violência. Esse imaginário, pelo contrário, é negado por essa narrativa.

A antologia de Ferréz - performer e produtor ligado à cena do hip hop de São Paulo -, se intitula Literatura Marginal: talentos da escrita periférica (2005), editado pela Editora Agir, livro que recolhe textos com uma maior militância, sem fugir da centralidade representativa da estética da violência. O manifesto de abertura à antologia intitula-se "Terrorismo Literário", escrito por Ferréz, figura central na consolidação da literatura marginal em São Paulo.

A capoeira não vem mais, agora Reagimos com a palavra, por que pouca Coisa mudou, principalmente para nós. Não somos movimento, não somos Novos, não somos nada, nem pobres Porque pobre, segundo o poeta da rua, é Quem não tem as coisas. Cala a boca, negro e pobre aqui não Tem vez! Cala a boca! Cala a boca uma porra, agora a gente Fala, agora a gente canta, e na moral Agora a gente escreve. Quem inventou o barato não separou Entre literatura boa /feita com caneta de Ouro e literatura ruim/escrita com Carvão, a regra é só uma, mostrar as Caras. Não somos o retrato, pelo contrário, mudamos o foco e tiramos nós mesmos a nossa foto (FERRÉZ, 2005, p. 9). 
O forte apelo ao real, à alteridade e à violência são temáticas importantes nessa antologia, contribuindo, mais uma vez, para a consolidação da narrativa dominante sobre a favela como espaço problemático e violento. Ao mesmo tempo, nesses textos, emerge a voz da comunidade que reivindica não apenas o seu espaço no mercado editorial, mas também luta por uma comunidade mais justa, promove ações e divulga eventos como festas literárias, saraus, bibliotecas comunitárias. Mediante a organização de saraus literários, o movimento de literatura marginal, até então restrito às publicações coletivas de Ferréz, consolida-se através do encontro de várias linguagens artísticas como a performance, o rap e a poesia. Sergio Vaz, por exemplo, cria a Cooperifa em 2001, movimento dos saraus literários em que os escritores assumem um papel de sujeitos colaborativos, engajados e participativos na comunidade, escrevendo poesia e narrativa de resistência. O termo "resistência", inicialmente concebido como um conceito apenas da ética e da política, passa a mergulhar no mundo da estética nesse novo contexto. Além disso, cabe lembrar também a Semana de Arte Moderna da Periferia, realizada em novembro de 2007. Nesse evento, ressaltou-se particularmente a posição engajada do escritor-morador da periferia, um "artista ao serviço da comunidade", como se afirma no "Manifesto da Antropofagia Periférica" elaborado por Sergio Vaz para esse evento. O caráter político do evento permitiu consolidar ainda mais a conduta engajada da literatura marginal.

Após essa breve reflexão sobre a literatura marginal da (e sobre a) favela, a meu ver, pode-se afirmar que ela se funde a partir do reconhecimento da periferia como espaço da alteridade, da centralidade e da consolidação da estética da violência e da marginalidade, discursos incorporados tanto pelos escritores da classe mais abastada, quanto pelos escritores mais periféricos. Desse modo, a representação da favela como gueto se fundamenta a partir de imagens simbólicas fixas e estabelecidas: o lixo, uma geografia particular de bairro constituída por ruelas, tiroteios, assaltos, consumo e tráfico de droga, vinganças, homicídios, traições, medo. Nessas representações, predominam, portanto, a romantização, a espetacularização da violência e do crime e a estetização da pobreza. O tema da violência é, assim, uma constante, como é possível detectar no texto de Carolina Maria de Jesus na década de 1960, em Fonseca na década de 1970, em Lins nos anos 1990 e em Ferréz nos anos 2000. Desse modo, como afirma Rodriguez (2003), também o escritor periférico não foge da reprodução do discurso dominante, destacando a dificuldade dessa experiência ao elaborar uma fala autônoma e diversa da narrativa dominante. A imagem da violência nos textos dos escritores periféricos

\begin{abstract}
É reforçada e reinventada, dotada agora de maior realismo e autenticidade, [...] devemos lembrar que quem narra possui a autoridade da vivência na favela. Esta mesma autoridade o legitima a optar por uma abordagem da favela que reproduz estigmas e preconceitos (RODRIGUEZ, 2003, p. 51).
\end{abstract}

Simultaneamente, a estética da violência no olhar dos escritores como Lins e Ferréz "não está apenas no plano factual e temático da obra, mas também se insere como uma subversão da norma culta" (PATROCÍNIO, 2006, p. 56). Isso sinaliza o fato de que ela emerge para denunciar injustiças, preconceitos, exclusão, discriminação, exploração, e a marginalização de quem vive essas realidades. Isso gera, portanto, uma ambiguidade, por se observar o tema da violência como eixo da narrativa dominante criada sobre a favela, mas também como dispositivo de denúncia e crítica da realidade opressora.

\section{O Bando Editorial Favelofágico}

Após essa breve reflexão sobre o tópico da favela na literatura brasileira, interessa discutir acerca da proposta cultural e literária do Bando Editorial Favelofágico, que consegue fugir da influência da narrativa e do discurso dominante - em que a violência é o elemento \fulcral, como constatado -, podendo a experiência favelofágica ser interpretada como criadora potencial de uma narrativa diferente a partir de um lugar de fala marginal e marginalizado. 
O objetivo do coletivo é a publicação de autores que se identificam com uma perspectiva contra-hegemônica com respeito ao padrão literário e social dominante. O Bando, além da função editorial e de publicação de livros, organiza eventos de promoção de escrita literária e outras manifestações artísticas. Junto com o coletivo de cultura e arte de Manguinhos, o Bando coordenou, por exemplo, a Agenda Cultural Mandela Vive, um calendário de eventos de criação, investigação e apresentações artísticas nos campos da literatura, da música, do teatro e das artes plásticas. A proposta do projeto é a de construir um movimento literário de escritores das classes populares do Rio de Janeiro, isto é, abrir as portas do mundo da literatura para quem pertence a classes sociais desfavorecidas, moradores das periferias e dos subúrbios, que dificilmente conseguem ser reconhecidos pelo cânone hegemônico e pelo mercado literário. Felipe Eugênio, escritor e editor do Bando, declarou em uma entrevista (VIANNA, 2015) que através da favelofagia, que definirei mais adiante, pretende-se dar voz aos que não pertencem ao círculo de escritores delineado em um estudo de Regina Dalcastagné, professora da $\mathrm{UNB}^{8}$. Na análise de Dalcastagné, constatou-se que "a maioria esmagadora dos autores publicados pelas grandes editoras são do sexo masculino, brancos e com alguma titulação acadêmica." (n.p.). Desse modo, os novos autores da literatura que o Bando Editorial Favelofágico promove costumam ser silenciados pelo cânone literário e não ouvidos pela maioria.

Somos negros, somos mulheres, somos travestis, somos o precariado, somos os alienados úteis, somos aqueles que escrevem mal, somos a potência do subúrbio, somos uns vermelhos, somos Carolina Maria de Jesus, somos Machado de Assis, somos Graciliano Ramos, somos Saramago, somos Luiz Ruffato, somos Nei Lopes, somos Conceição Evaristo. (Um pouco sobre o Bando Editorial Favélofagico, s.f.) ${ }^{9}$

O coletivo visa realizar práticas socioculturais que pretendem romper com o elitismo do mundo literário e isso se torna possível ao se "ampliar a quantidade de autores provenientes dos estratos sociais mais vulnerabilizados e, a partir daí, criar estratégias para o aumento do número de leitores nos subúrbios, favelas e rincões brasileiros." (Um pouco sobre o Bando Editorial Favélofagico, s.f.). Desse modo, tenciona-se não apenas impulsionar a palavra e a escrita dos silenciados e dos não ouvidos, mas também fomentar a prática da leitura na população das periferias. Assim como na literatura marginal da primeira década de 2000 em, São Paulo, o movimento favelofágico buscou marcar o lugar a partir do qual falar e narrar: a favela e a periferia, sendo essas concebidas como outra possibilidade do fazer literário. A crítica à lógica mercadológica tradicional que domina a indústria literária é reclamada pelo coletivo, considerada um meio que dificulta aos que não são reconhecidos pelo cânone literário ${ }^{10} \mathrm{O}$ acesso a um campo social e simbólico, que é, de fato, dominado por "condições assimétricas, de elogios individualistas, de base racista, elitista e, quando não, complacência etnocêntrica" (Um pouco sobre o Bando Editorial Favélofagico, s.f.). Essa crítica aproxima o coletivo favelofágico ao movimento da poesia marginal dos anos 1970, já que ambos recusam os mecanismos mercadológicos tradicionais: os poetas marginais eram editores e distribuidores das próprias obras, enquanto que o Bando Editorial Favelofágico nasce como uma organização sem fins lucrativos, que não demanda a venda de livros para sua existência e sustentação. O lucro, portanto, não é interesse da organização, que, como projeto estéti-

\footnotetext{
8 Disponível em: https://www.recantodasletras.com.br/artigos-de-literatura/4077054: link do breve artigo-entrevista em que se discute sobre o estudo de Regina Dalcastagné.

99 O site não está mais disponível para consulta.

${ }^{10}$ Por cânone literário, entende-se o "conjunto de obras literárias que, num determinando momento histórico, os intelectuais e as instituições dominantes ou hegemônicas consideram ser os mais representativos, os de maior valor e autoridade numa dada cultura oficial" (SANTOS, 1998, p. 10). O cânone literário assume a "função de garante da identidade e da estabilidade nacional e cultural" (SANTOS, 1998, p. 10).
} 
co-político se coloca na contramão artística, cultural e social do mercado literário, que frequentemente silencia e exclui os que não se encaixam no modelo. "Produzir autores e fazer os livros chegarem às pessoas" (VIANNA, 2015) é o objetivo do movimento, como afirma Eugênio Felipe. Resulta evidente que a crítica às lógicas mercadológicas identifica um posicionamento ideológico claro assumido pelo coletivo, isso é, uma postura contra-hegemônica; de fato, o coletivo visa formar olhares politizados e críticos sobre a realidade social, designando assim o campo literário como um espaço de luta e de resistência. O Bando Editorial Favelofágico, desse modo, escolhe a literatura como instrumento (ou arma) através do qual refletir sobre a sociedade e por meio do qual fomentar a transformação social, que será desempenhada pelos escritores definidos como "operários da palavra" (Um pouco sobre o Bando Editorial Favélofagico, s.f.), expressão que permite enfatizar a condição social dos escritores favelofágicos, pertencente às classes trabalhadoras e mais desfavorecidas. Através das palavras dos operários, tenciona-se desenvolver um projeto composto por vozes abafadas, que poderá revolucionar os imaginários e subverter o status quo literário e social.

A partir do conceito de Favelofagia, desse modo, inaugura-se a reflexão sobre novos e potenciais paradigmas estéticos. O neologismo Favelofagia compõe-se do termo favela, agregando ao sufixo grego - fagia - que significa "alimentar-se de". Nesse sentido, a expressão sinaliza o ato de se alimentar da favela, das ideias, das experiências vividas e dos pensamentos surgidos nesses espaços, mas também se alimentar do outro, do próximo, do diferente, do desconhecido. A Favelofagia caracteriza-se por uma pluralidade de reflexões e de narrativas e o elemento que denota sua especificidade é a clara demarcação do lugar de enunciação e de fala, a partir do qual as reflexões e as narrativas dos escritores surgem e se propagam. O coletivo favelofágico tenciona criar uma literatura que amplie os sentidos a partir da visão do explorado, do submisso, do sub-representado, uma visão sobre o mundo não abstrata, mas real, concreta, tangível e corpórea, para que novos horizontes culturais, políticos e sociais surjam: “É tempo de editar os contos dos sem réis, os contos sem réis" (Manifesto Favelofágico, s.f.), como se afirma na conclusão do Manifesto Favelofágico.

\begin{abstract}
Temos na favelofagia uma proposta de criação artística na qual a assinatura é a do sujeito consciente de sua condição de classe e identidade étnica. No caso brasileiro, estamos falando de um escritor pobre, comumente não-branco, por vezes morador de favela e que, de modo livre, produz ficção (VIANNA, [2015]).
\end{abstract}

O movimento favelofágico evoca a experiência artística do movimento cultural antropofágico, corrente artística modernista da década de 1920 no Brasil, cuja proposta teórica é apresentada no "Manifesto Antropofágico", ou Antropófago, publicado por Oswald de Andrade na Revista de Antropofagia, em 1928. Literalmente, a antropofagia significa a ação de comer carne humana, também definido canibalismo, um ritual praticado por algumas tribos indígenas, nas quais só se comia a carne dos inimigos valentes para incorporar suas qualidades positivas, como a bravura e a coragem. O conceito de antropofagia refere-se, nesse contexto, à "deglutição" dos estilos e modelos internacionais para a produção de algo totalmente novo e com a cara do Brasil, combatendo o eurocentrismo da arte. No manifesto, Oswald reconhece na antropofagia, um ato de vindita menos bárbaro do que a crueldade com que os europeus, incapazes de comer um homem morto, torturam e estraçalham um corpo vivo. Protagonista antropofágico é o índio, o canibal, que na visão proposta no manifesto por Oswald, se torna um sujeito transformador, social e coletivo, permitindo revisar a concepção estabelecida pela tradição ocidental que tolerava o canibalismo e oferecendo, portanto, um diferente modelo de pensamento cultural brasileiro. Na proposta de Oswald, a ação antropofágica da deglutição, tem como objetivo metafórico o ato de "comer" a cultura do outro externo, como a norte americana e europeia e do outro interno, como a cultura ameríndia, afrodescendente, eurodescendente 
e dos descendentes orientais. Oswald reconhece que não se deve negar a cultura estrangeira, mas não se deve imitá-la, transformando-a no único modelo de referência para a cultura brasileira e recusando tudo o que for regional e local. No manifesto antropófagico, Oswald não se refere a um processo de assimilação harmoniosa entre os dois mundos, como o autor auspicava no "Manifesto da Poesia Pau-Brasil” de 1924. No manifesto de 1928, debate sobre a deglutição crítica do outro, - o moderno e civilizado -, e cria um horizonte utópico, - aquele de substituir o sistema burguês patriarcal europeu com o matriarcado da comunidade primitivo -, promovendo, portanto, uma "revolução caraíba". Por influência do movimento antropofágico da década 1920, o coletivo favelofágico tenciona paralelamente "antropofagizar a literatura contemporânea através de uma perspectiva de classe, gênero e identidade étnica" (VIANNA, [2015]), isso é deglutir a literatura contemporânea clássica, adotando uma perspectiva mais consciente e politizada, no que se refere às questões de gênero, classe e identidade étnica. A partir da leitura de clássicos como Carolina Maria de Jesus e Lima Barreto, elabora-se "favelofagicamente" "c uma literatura engajada, em que emerge a consciência da condição social, étnica e religiosa do escritor, consciência que se transforma em catalisador para tecer e propagar os escritos.

Mordemos a literatura brasileira, trazendo de seu cânone literário aquelas obras que alcançam essa dimensão crítica que nos interessa. Não inventamos roda alguma. Graciliano Ramos, João Cabral de Melo Neto, Lima Barreto, Carolina Maria de Jesus, Vianninha, Augusto Boal, Guarnieri, o próprio Machado de Assis, Érico Veríssimo, entre outros, além de contemporâneos como Nei Lopes, Ferréz, Conceição Evaristo e Luiz Ruffato, são exemplos que ofertam caminhos para refletir sobre a literatura que enfrenta, no lugar daquela que omite ou obedece (VIANNA, [2015]).
Desse modo, compreende-se que há uma grande consideração dos clássicos; retomam-se os grandes da literatura brasileira que incorporaram uma visão preocupada e crítica sobre a sociedade e suas épocas para serem analisados, estudados, criticados. Portanto, não se recusa o outro externo - nesse caso os grandes clássicos -, mas se estabelece um diálogo e uma relação com as obras que constituem o cânone literário e que conservam uma dimensão crítica sobre a sociedade. A partir das reflexões produzidas coletivamente, tenciona-se produzir novas literaturas decoradas por novos paradigmas, construídas a partir de um lugar de enunciação não usual: "Produzir o novo, de uma nova forma, de um novo lugar" (Manifesto Favelofágico, s.f.), como constatado no Manifesto Favelofágico. Os escritores favelofágicos fazem literatura "malcriada" e histórias que raramente se encontram nas livrarias: "histórias enegrecidas, histórias suburbanas, histórias transgêneras, histórias do trabalhador braçal e do intelectual que mora na favela", (VIANNA, [2015]), diz Eugenio Felipe, histórias que nascem a partir das experiências que mobilizam a "vida justa das pessoas" e o "peso insuportável do mundo injusto". Portanto, "o proganista antropofágico" da corrente favelofágica é a classe trabalhadora, o morador da favela e das periferias, como destacarei mais adiante. A Favelofagia é insurgente e transita pelo mundo da literatura como movimento ideologicamente rebelde, como uma "revolução caraíba", como forma de resistência aos modelos artísticos e culturais reconhecidos e canônicos, no intuito de "desfigurar a cultura vigente", concordando assim com as palavras de Francavilla (2012, p. 70, tradução nossa): "Rebelar-se artisticamente sinaliza de imediato uma forma de resistência à opressão" ${ }^{11}$. Felipe Eugênio, de fato, afirma na entrevista que o movimento favelofágico tenciona contribuir para a mudança do mundo literário.

\footnotetext{
Nos interessa a literatura que se sente incomodada com o mundo. Ela muda o mundo? Não diretamente, é claro. Mas se modificarmos o mundo literário, já estaremos satisfeitos. Apenas
}

${ }_{11}$ Do original: Ribellarsi artisticamente rivela giá di per se una forma di resistenza all'oppresione. 
queremos deixar claro que o universo literário pode e deve ser disputado. A favelofagia não traz a favela para a literatura, ela expõe que os reis têm andado nus por aí. Mas esse conceito-nome [favelofagia] nos denuncia. E aí, parafraseando o Augusto Boal, nada de ser equidistantes, nós tomamos partido (VIANNA, [2015]).

O horizonte utópico que os favelofágicos querem alcançar visa criar um novo mundo, mais especificamente um novo mundo literário. Assim sendo, a literatura que os favelofágicos tencionam modelar, como afirmado no manifesto do Bando, fundamenta-se na filosofia da práxis ${ }^{12}$, retomando assim o pensamento de Gramsci. Teoria e prática se juntam, palavra e ação se amalgamam e a partir desse encontro, gera-se uma literatura de palavras que transforma, que não passa inobservada e indiferente, impregnada de poder e de resistência: "minha língua é navalha”, recita Gato Preto em seu conto presente na antologia da Literatura Marginal (2005, p. 68). Paralelamente, no Manifesto Favelofágico, seus escritores replicam: "[...] queremos ver se é possível sendo senhores da palavra e sabotadores da palavra, possam devorar com as palavras [...]" (Manifesto Favelofágico, s.f.). Dessa forma, tanto a literatura favelofágica, quanto a literatura marginal de São Paulo visam à elaboração de:

Textos de militância social, símbolo de um conflito latente e da posição radical assumida por parte de muitos jovens escritores favelados; de experimentação mediante o uso do léxico da favela; com seu slang complexo, fantasioso e denso de conexões exógenas; de comunicação intertextual com as linguagens da cultura erudita e daquela popular ${ }^{13}$ (FRANCAVILLA, 2012, p. 78 , tradução nossa).
Linguagens e literaturas plurais que geram práticas estéticas e políticas nesses dois contextos que se assemelham: o Manifesto Favelofágico recorda muito, de fato, o manifesto da literatura marginal elaborado por Ferréz, intitulado Terrorismo literário, citado acima. Ambos adotam uma linguagem direta, belicosa e crua e com recursos ao léxico da favela e da rua; questionam a necessidade de mudança e de crítica por meio da arte e criticam fortemente os modelos hegemônicos (certas vezes, de forma maniqueísta).

\begin{abstract}
A favela morde, come e digere o mundo via literatura", "Mas o mundo é indigesto, ó, Esteves!", uma voz de fora grita na nossa janela. É verdade, vozinha! Pra isso é que usamos o fígado. Sim, leitor, que nos acompanha até essa fase de compreensão fisiológica: temos um fígado que secreta a bile da filosofia da práxis (Manifesto Favelofágico, s.f.).
\end{abstract}

No Manifesto Favelofágico, critica-se, por exemplo, a academia que, a partir da década de 1990, apropria-se do tópico favela, tornando-o um modismo temático e um "campo sistematicamente utilizado para estudar as mais várias questões ligadas à pobreza" (VALLADARES, 2006, p. 163). Os favelofágicos sublinham que a favela "não será comida do bandejão universitário", mas seus moradores se transformarão em operários da palavra e "é dali, da favela, que faremos a literatura - a mais fantástica que for" (Manifesto Favelofágico, s.f.).

Além disso, os favelofágicos estão cientes de que a literatura pode ser um potente dispositivo criador de estereótipos e imaginários que contribuiu, sobretudo, através das transposições cinematográficas dos textos literários (basta pensar no livro e filme Cidade de Deus) para a construção de uma realidade

\footnotetext{
${ }_{12}$ Discutindo acerca da tese XI de Marx, que propõe mudar o mundo e não apenas interpretá-lo, segundo Gramsci essa tese "non può essere interpretata come un gesto di ripudio di ogni sorta di filosofia", mas como "l'egemonica affermazione di unitá fra teoria e pratica [...]. Se ne deduca anche che il carattere della filosofia della praxis è specialmente di essere una concezione di massa, una cultura di masse" (GRISONI; MAGGIORI, 1975, n. p.). E afirma que: "per la filosofia della praxis, l'essere non può essere disgiunto dal pensare, l'uomo dalla natura, l'attività dalla materia, il soggetto dall'oggetto; se si fa questo distacco si cade in una delle tante forme di religione o nell'astrazione senza senso" (GRISONI; MAGGIORI, 1975, n. p.).

13 Do original: Teste di militanza sociale, segno di un conflitto latente e della posizione radicale assunta da parte di molti giovani scrittori favelados; di sperimentazione, com il ricorso al lessico della favela; com il suo slang complesso, fantasioso e denso di incastri esogeni; di comunicazione intetertestuale com i linguaggi della cultura erudita e di quella populare .
} 
homogeneizada sobre as periferias e as favelas, em que a violência, a criminalidade e a pobreza imperam.

Quase metade dos filmes de grande circulação do cinema são originários da literatura, o que nos leva a perceber que a literatura quase que compreende metade do universo de telespectadores que é massificado no grande cinema, cinema que aparece no Netflix, cinema dos "cinemões". A literatura invade novelas, séries. A literatura cria tipos: ela reconhece e reafirma estereótipos - assim como ela pode ser também reativa em relação a eles (Um pouco sobre o Bando Editorial Favélofagico, s.f.).

Como afirmado na citação acima, a literatura, além de criar e reproduzir estereótipos que essencializam, reduzem e menosprezam as favelas, pode gerar, por exemplo, por meio da Favelofagia, novos paradigmas e novas leituras, novos sentidos e novas percepções sobre as periferias. É, de fato, o propósito do Bando Editorial Favelófagico, que através do dispositivo-literatura oferece imagens múltiplas e distintas, diversificando-as com relação àquelas que a narrativa dominante costuma divulgar. A literatura favelofágica torna-se um instrumento para produzir contranarrativas literárias sobre as periferias, comprometendo-se a divulgar proposições e leituras sobre outros mundos. Desse modo, através da subversão desses estereótipos, dá-se ênfase à potência e à vitalidade desses espaços, que permanecem sendo abaladas pela narrativa dominante.

A estética da violência, por exemplo, é um dos eixos centrais que a literatura e o cinema ergueram ao retratar a favela, como constatado acima: explícita e cruenta na Cidade de Deus de Paulo Lins e apropriada como instrumento de denúncia e de crítica pela literatura marginal de 2000. A violência manifesta-se, portanto, por meio da literatura "como tema, como matéria social, matéria do texto, violência na linguagem e violência como projeto" ${ }^{14}$
(FRANCAVILLA, 2012, p. 70, tradução nossa). Nos dois casos citados, reconhece-se a violência como elemento constituinte da realidade favela, como já constatado. Por outro lado, a literatura favelofágica recusa reconhecer esse símbolo como componente principal nos contos que representam as favelas ou nos textos narrados a partir desse lugar. A violência, segundo o coletivo carioca é, sim, uma questão real nos bairros periféricos em que ocorrem conflitos armados latentes, assim como decorre no complexo de Manguinhos; contudo, não se aceita essa imagem como único símbolo dessa realidade, tencionado criticar e escapar de sua espetacularização e romantização; a violência é concebida como estigma que mancha todas as experiências e vivências que lá decorrem. O favelofágico é contra a imagem da favela como produtora da violência espalhada pela narrativa dominante, mas que é também reapropriada pelo discurso do sub-representado, como ocorre em Lins e em Ferréz. Tenciona-se romper com a visão da favela como território de exceção; pelo contrário, pretende-se enfatizar a humanidade, a criatividade e a riqueza que se espalha através da arte e da cultura que lá nascem, lugar de disputa para novas possibilidades políticas e sociais, como resposta a um mundo desigual e injusto. Desenvolve-se, desse modo, uma atitude contra a estereotipagem, contra os valores estabelecidos e dominantes na procura da diversidade e de novas estéticas.

Grãos imastigáveis ${ }^{15}$ é o primeiro fruto desse projeto literário e "primeiro experimento favelofágico".Resultado da primeira residência literária em 2015, o livro é uma antologia de contos de ficção elaborados por treze escritores, que, incentivados por oficinas literárias, pelos intercâmbios de ideias e de experiências, pela vivência coletiva e pelas divagações urbanas pela cidade do Rio, escreveram contos fictícios, porém com uma grande dose de realismo, sobre os dramas da classe trabalhadora, as histórias, as emoções, as tristezas, as preocupa-

\footnotetext{
14 Do original: como tema, como materia sociale, materia del testo, violenza nel linguaggio e violenza come progetto.

15 Referência direta ao verso da poesia "Catar Feijão" de João Cabral de Melo Neto: "um grão imastigável, de quebrar dente". O poema faz parte do livro A Educação pela pedra (1997), cuja primeira edição foi publicada em 1965.
} 
ções, os desejos, os desconfortos, as dificuldades, os sofrimentos de seus personagens. Os protagonistas vivem o cotidiano da cidade, pela qual não param de transitar, por seus subúrbios, suas favelas, suas áreas centrais; mas há também personagens com histórias encenadas em ambientes rurais.

Travestidos de garis, de técnicos de informática, de professores do ensino público, de integrantes da velha guarda de escola de samba, de agitadores culturais, de militantes de movimento negro, de carnavalescos, de estudantes universitários, de atrizes, de funcionários públicos e de marceneiros, esses autores favelofágicos podem estar agora mesmo, sem pose nem pompa, ao lado do seu leitor durante uma viagem de ônibus (Grãos Imastigáveis, 2016, p.10).

Cabe ressaltar, como já constatado, que não necessariamente se retrata a favela, mas escolhem-se também outros cenários. Isso implica pensar que a Favelofagia e os contos favelofágicos em questão não mostram uma visão fechada da favela em si mesma, mas apresentam uma realidade que comunica com outros espaços urbanos e também rurais. A Favelofagia abre-se ao mundo e se funda a partir da pluralidade temática que emerge nos contos do livro Grãos Imastigáveis, uma perspectiva que dificilmente esbarra em outras literaturas, que seleciona a favela como temática e cenário a ser representado, quebrando assim a ideia de que os moradores da favela podem narrar apenas histórias sobre suas realidades.

Desse modo, a Favelofagia fundamenta-se a partir de uma estética barroca, porque a pluralidade temática e dos cenários que afloram a partir do espaço-favela permite vislumbrar a abrangência e o potencial criativo dessa. Esse lugar de enunciação a partir do qual quebrar os paradigmas da beleza, do belo, do perfeito, encara o padrão literário hegemônico, que continua a reproduzir e preservar tais valores. Francavilla (2012, p. 77, tradução nossa) atribui ao espaço da favela o conceito de barroco associando à ideia babélica de desordem e confusão, elementos que caracterizam a narrativa dominante, como afirmado neste trecho.

Em termos de percepção estética, discutiu-se sobre a favela como manifestação do barroquismo, eterna reescritura da paisagem urbana através de forma de reciclagem e de junção casual, patchwork, bricolagem e, sobretudo híbrido, incluindo esse espaço no panorama pós-moderno. Não apenas a literatura, mas também o cinema, a arte e a fotografia continuam a relevar o código babélico composto por materiais juntados caoticamente, perigosamente indiferente às regras básicas de segurança e às consequências naturais da meteorologia $\mathrm{e}$ opostos às formas geométricas e regulares do centro. Um rizoma inconcluso e declinado, em desordem e excesso e contra diferenciado pela edilícia de forma mísera, sem coordenadas arquitetônicas plausíveis ${ }^{16}$.

Do meu ponto de vista, seria inovador conceber a favela dos contos favelofágicos como resultado de uma concepção barroca, e sustento-me na proposta de Santos (1998, p. 133), que a interpreta como um lugar plural, aberto, com um poder e uma "imaginação centrífuga, subversiva e blasfema". O barroco, desse modo, corresponde na leitura de Santos (1998, p. 357-358) a "uma metáfora cultural para designar o tipo de subjetividade e de sociabilidade capaz de explorar e de querer explorar as potencialidades emancipatórias da transição paradigmática. [...]”. Debate-se, assim, sobre a posição de "marginalização que possibilitou uma criatividade cultural e social

16 Do original: In termini di percezione estetica si é parlato della favela come manifestazione del barrocchismo, perenne riscrittura del paesaggio urbano attraverso le forme del riciclaggio e dell'aggiunta casuale, patchwork, bricolage, e soprattutto ibrido, elevandola cosi a luogo a metafora facilmente includibile nel copioso arsenale del postmoderno. Non soltanto la letteratura ma anche il cinema, l'arte e la fotografia ne continuano a rilevare il codice babelico composto di materiali assemblati senza libretto di istruzioni, pericolosamente incuranti delle elementari regole della sicurezza e delle conseguenze naturali della meteorologia e opposti all'ordito geometrico e regolare del centro. Un rizoma inconcluso e declinato in disordine ed eccesso e contraddistinto da edilizia di tipo infimo, privo di plausibili coordinate arquitettoniche. 
específica, diversificadamente elaborada em múltiplas combinações, ora altamente codificada, ora caóticas, ora eruditas, ora populares, ora oficiais, ora ilegais [...]" (SANTOS, 1998, p. 357-358).

Isso posto, a multiplicidade temática, a liberdade criativa de expressão, o distanciamento do cânone literário, a consideração dos clássicos engajados, a pluralidade dos cenários, o ecletismo e a variedade dos personagens criados a partir das perspectivas dos escritores periféricos são os marcos da Favelofagia, cujo projeto se apresenta como contra-hegemônico, plural, politizado, engajado, livre dos cânones e com sede de uma prática e de transformação. Concebendo-a como uma nova manifestação dentro da literatura marginal, o coletivo favelofágico posiciona-se longe do cânone literário, atuando como uma literatura menor, categorizada como tal não por ser protagonizada por uma minoria, mas por sua "[...] condição potencialmente revolucionária" (FRANCAVILLA, 2012, p. 9, tradução nossa $)^{17}$, como confirma Francavilla, segundo o qual, essa característica é intrínseca a todas as literaturas menores, por ser sua oposição inovadora e insurgente respeito à literatura padronizada. A margem pode ser um lugar de novas possibilidades artísticas e literárias, podendo subverter o padrão hegemônico que, de fato, contribui para a visão da literatura como um mundo privilegiado da elite letrada. Os "iletrados", ou melhor, os "não privilegiados", isso é, os escritores marginais, "reclamam o direito de falarem por si mesmos, sem os frequentes (sic) mascaramentos impostos quando abordados a partir de uma perspectiva do centro para a periferia” (BENVENUTO, 2006, p. 2).

\section{Considerações finais}

Finalizando, o Bando Editorial Favelofágico tenciona, portanto, apresentar a periferia como espaço de luta e de transformação que proporciona novos sentidos ao conceito de periferia por meio de interpretações plurais e multifacetadas, recusando o imaginário e as narrativas hegemônicas. O coletivo retrata a periferia como um espaço de fala plural, a partir do qual seus moradores contribuem para constituir novos cânones, novos paradigmas literários, políticos e sociais, recusando as lógicas mercadológicas tradicionais e a narrativa dominante da violência que tira do foco qualquer outra leitura e concepção sobre esse espaço.

\section{Referências}

ANDRADE, C. D. (2007). Favelário nacional. In: Corpo (pp. 111-127). Rio de Janeiro: Favelário Nacional. Record.

BENEVENUTO, S. J. Literatura marginal: A escrita como arma e instrumento de inserção cultural. Texto integrante dos Anais do XVIII Encontro Regional de História: O historiador e seu tempo, ANPUH/SP - UNESP/Assis, 2006.

DE HOLLANDA, Heloise Buarque. Entrevista Viva Favela. (2007). Disponível em: http://www.heloisabuarquedehollanda.com.br/viva-favela/

FELIPE, E.; TARUMIM, F. Grãos Imastigáveis: Contos Favelofágicos. Rio de Janeiro: Bando Editorial Favelofágico, 2006.

FERREIRA, T. M. Entre Becos e Tetos de Zinco: Paisagens de um Favelário Nacional. Scripta, v. 11, n. 20, p. 309-348, 2007. Disponível em http://www.pucminas.br/imagedb/ documento/DOC DSC NOME ARQUI20080716151218. pdf?PHPSESSID=7e3aegfo $49 \mathrm{fb} 49144802 \mathrm{e} 53 \mathrm{cc} 86848 \mathrm{fe}$

FERRÉZ. Literatura Marginal. Talentos da Escrita Periférica. Rio de Janeiro: Agir, 2005.

FONSECA, R. Romance Negro e Outras Histórias. Rio de Janeiro: Companhia das Letras, 1992.

FONSECA, R. A arte de andar pelas ruas do Rio de Janeiro. In: SCHNAIDERMAN, B. (org.). Contos reunidos. São Paulo: Companhia das Letras, 1994.

FRANCAVILLA, R. Voci del Margine. Roma: Artemide, 2012. GOMES, R. C. Todas As Cidades, A Cidade. Rio de Janeiro: Rocco, 1994.

Grãos Imastigáveis. Bando Editorial Favelofágico. Disponível em http://www.favelofagia.com/livro-1

GRISONI, D.; MAGGIORI, R. Guida a Gramsci. Milano: BUR, 1975 .

JESUS, C. M. Quarto de despejo: diário de uma favelada. São Paulo: Ática, 2007.

LINS, P. Cidade de Deus. Rio de Janeiro: Companhia das Letras, 1997.

MANIFESTO Favelofágico. Bando Editorial Favelofágico.

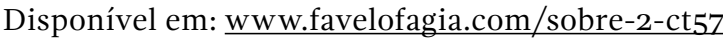

${ }_{17} 17$ Do original: [...] condizione potenzialmente rivoluzionaria. 
MELO, J. C. A Educação pela Pedra. Rio de Janeiro: Editora Nova Fronteira, 1997.

MELO, P. Inferno. Rio de Janeiro: Companhia das Letras, 2000.

Nascimento, É. P. Literatura Marginal: os Escritores da Periferia entram em Cena. Especialização (Pós-Graduação em Antropologia Social) - USP, São Paulo, 2006. https://doi. org/10.11606/d.8.2006.tde-03092007-133929

PATROCÍNIO, P. R. T. Entre o Morro e o Asfalto: Imagens da Favela nos discursos culturais brasileiros (Dissertação de Mestrado em Letras) - PUC, Rio de Janeiro, 2006. Disponível em: https://www.academia.edu/10496093/Entre o morro e o asfalto imagens da favela nos discursos culturais_brasileiros https://doi.org/10.17771/pucrio.acad.8987

RODRIGUEZ, B. M. Mutirões discursivos: literatura e vida comunitária nas periferias urbanas. Estudos de Literatura Brasileira Contemporânea, Brasília, v. 22, p. 47-61, 2003.

SANTOS, B. de S. Tempo, Códigos Barrocos e Canonização. Revista Crítica de Ciências Sociais, v. 51, p. 3-20, 1998.

UM POUCO sobre o Bando Editorial Favélofagico. Bando Editorial Favelofágico. Disponível em http://www.favelofagia. com/quem-somos

SILVA, F. Q. da. A literatura marginal (periférica) no contexto contemporâneo. Horizonte Científico, v. 3, n. 1, p. 1-31, dez., 2008.

VALLADARES, L. do P. A invenção da favela: do mito à origem da favela.com. Rio de Janeiro: Ed. da FGV, 2006. https://doi. org/10.11606/t.16.2014.tde-07072014-112828

VARELLA, D. Estação Carandiru. Rio de Janeiro: Companhia das Letras, 1999.

VIANNA, B. O olhar poético não combina com alienação. Bernardovianna.com, 27 nov. 2015. Disponível em: http:// bernardovianna.com/o-olhar-poetico-nao-combina-com-alienacao/ https://doi.org/10.25094/rtp.2019n26a553

Recebido em: 27/8/2018.

Aprovado em: 15/4/2019.

\section{Luana Loria}

Universidade Federal De Santa Catarina (UFSC)

Orcid: https://orcid.org/0000-0002-5439-9251

E-mail: luanalo2689@gmail.com

\section{Breve Biografia}

Doutora Interdisciplinar em Ciências Humanas pela Universidade Federal de Santa Catarina (Brasil) (2014-2017) e ex-bolsista do programa Fellow Mundus (Erasmus Mundus). Estuda principalmente manifestações artísticas e políticas das periferias do Rio de Janeiro e de Lisboa. Mestre em "Crossways in Cultural Narratives" (Programa Erasmus Master
Mundus) em 2014 pelas Universidade de Santiago de Compostela, (Espanha), Universidade Nova de Lisboa, (Portugal) e Universidade de Sheffield, (Reino Unido). Graduada em Línguas, Literaturas e Estudos interculturais (2011), com especialização em Língua Portuguesa e Culturas de Países de Língua Portuguesa, pela Universitá Degli Studi di Firenze, Itália. Tem experiência nas áreas de Literatura, Cinema, Filosofia, Educação, História, Estudos Culturais, Estudos pós-coloniais e decolonias, Estudos Urbanos, com ênfase no estudo de culturas das periferias dos países de língua portuguesa (especialmente Brasil, Portugal e Angola)

PhD in Human Sciences from the Universidade Federal de Santa Catarina (Brazil) (2014-2017). Her focus is mainly on artistic and political manifestations of the peripheries of Rio de Janeiro and Lisbon. Master in «Crossways in Cultural Narratives» (Erasmus Master Mundus) in 2014 by the Universidad de Santiago de Compostela, (Spain), Universidade Nova de Lisboa, (Portugal) and University of Sheffield, (United Kingdom). Bachelor in Languages, Literatures and Intercultural Studies (2011), with specialization in Portuguese Language and Cultures of Portuguese Language Countries, by Universitá Degli Studi di Firenze, Italy. She has experience in the areas of Literature, Cinema, Philosophy, Education, History, Cultural Studies, Postcolonial Studies and Decolonial Studies, Urban Studies, with emphasis on the study of cultures from the peripheries of Portuguese speaking countries (especially Brazil, Portugal and Angola).

Endereço de correspondência: Rua da Bempostinha, 86, Lisboa, Portugal. 